\title{
Modelling Entrepreneurial Attitudes in Women Entrepreneurs with Bayesian Networks
}

\author{
Jorge López ${ }^{1}$, Alicia Ramírez ${ }^{2}$, Pilar Casado ${ }^{2}$ \\ ${ }^{1}$ Department of Human and Social Sciences, Universidad de Almería, Almería, Spain \\ ${ }^{2}$ Department of Company Direction and Management, Universidad de Almería, Almería, Spain \\ Email: \{jpuga, aramirez, mbelmont\}@ual.es \\ Received December $17^{\text {th }}, 2011$; revised January $15^{\text {th }}, 2012$; accepted February $17^{\text {th }}, 2012$
}

\begin{abstract}
The entrepreneurial attitude model is nowadays getting more attention as a framework to explain and describe new business creation. In short, the attitude model posits that the entrepreneurial behavior is a planed action conditioned by the potential entrepreneur's attitudes which depends on desirability and feasibility beliefs. We have developed and compared three different Bayesian net models taking into account the principles of the Shapero's entrepreneurial event model. We have also modeled feasibility using two different dimensions. Firstly, we considered opportunity feasibility dimension referring to the degree in which a business would be successful attending to the market opportunities or demands. Secondly, we included a dimension of resources feasibility referring to the feasibility of the business in terms of the availability of possible resources to make the company a reality. The first model contained both feasibility dimensions whereas the other two only contained one dimension. Our results show that the Bayesian model containing the two forms of feasibility is better to predict entrepreneurial intentions. Implications in the context of promoting entrepreneurial attitudes and behaviors amongst women are finally discussed.
\end{abstract}

Keywords: Entrepreneurship; Attitudes; Bayesian Networks; Women; Model Comparisons

\section{Introduction}

Entrepreneurship is a key phenomenon in post-industrial economies to understand its social realities and it is said that it yields positive effects in the global and local productive markets. It seems that the time in which huge corporations made their livings using cheap labor force in some regions is over. As suggested by Shapero (1981), the old model of economy development based on exploiting low qualified human resources in some regions is less desirable in a long run as compared with a self-renewing local economical system supported by small and new created firms. In spite of the drawbacks concerning the study of entrepreneurship from a methodological point of view (i.e., Hébert \& Link, 1989; Rogoff \& Lee, 1996), the phenomenon is seen as an issue needing careful attention from social sciences because of its social usefulness. For example, Shapero (1985) stated that "entrepreneurship provides communities with the diversity and dynamism that not only assures continuous development, but also an environment in which personal freedom and individual rights can flourish" (p. 5) more than three decades ago.

\section{Entrepreneurial Attitudes}

The concept of entrepreneur is quite elusive and difficult to apprehend. As noted by Rogoff \& Lee (1996), we can perceive the effects of entrepreneurship but we cannot clearly see the nature or essence of the phenomenon. The concept of entrepreneur could be rooted to the Irish economics theorist Richard

${ }^{*}$ This research contains complementary results to those presented in the $4^{\text {th }}$ International Conference of Education, Research and Innovation (López, Ramírez, \& Casado, 2011) generated by the Woman Entrepreneur Research Team at the Universidad de Almería.
(Hayek, 1985). From Cantillon (1755-2010) point of view, the entrepreneur is the key to understand the dynamic of an economical system because the entrepreneur is a social agent coping efficiently with uncertainty and making the system evolve. Considering the entrepreneur as a social actor who flexibly faces uncertainty is also an idea stressed by recent theorists (i.e., Hébert \& Link, 1989; Polopolus \& Emerson, 1991; Samuelson, 1970).

There are a wide range of definitions of entrepreneur in social science research literature. For example, Hébert \& Link (1989) using a synthetic and historical approach stated that an entrepreneur is "someone how specializes in taking responsibility for and making judgmental decisions that affect the location, the form, and the use of goods, resources or institutions" (p. 39). We can find a different definition in Gartner (1988) who, from a functional point of view, considers that an entrepreneur is "a role that individuals undertake to create organizations" (p. 30). From a methodological point of view, Huefner, Hunt \& Robinson (1996) defined entrepreneurs as "those who said they were entrepreneurs and had owned and managed one or more business" (p. 62). In any case, and generally speaking, we could accept the definition introduced by McKenzie, Ugbah, \& Smothers (2007) and consider that an entrepreneur is person or group of people who seek to exploit an economic opportunity.

The traits model is probably the most commonly used in the research field of entrepreneurship. The model states that an entrepreneur person is that one who has or exhibits a set of stable psychological traits. Although the model has received several critics (i.e., Bird, 1988; Gartner, 1985, 1988), it was the reference framework until the mid eighties to address the research topic of entrepreneurship (i.e., Fuller-Love, 2006; McKenzie et al., 2007; Thompson, 2004). For example, McCle- 
lland $(1955,1961)$ pointed out that certain psychological traits like need for achievement were associated with the process of business creation. Traits like achievement motivation, intelligence, risk tolerance, self-efficacy, optimism or locus of control have been powerfully related with the phenomenon of entrepreneurship (i.e., Gottfredson, 1998; Huefner et al., 1996; Stanworth, Stanworth, Granger, \& Blyth, 1989). However, as stressed by Robinson, Stimpson, Huefner \& Hunt (1991), we could criticize four aspects of the traits model. First, the model may be criticized because the methodologies based on psychological traits research were not adapted to the specific field of entrepreneurship. As a result, the measurement instruments generally used in psychological research were used in the entrepreneurship context without adapting its contents threatening content validity standards. Secondly, personality theories were neither adapted from psychology to the entrepreneurship area. On the third place, some problems with convergent validity indexes were observed because the heterogeneity of scales used to measure the same construct correlated poorly. Finally, the traits model did not pay too much attention to the interactive theories which were beginning to develop in those days.

A new perspective originated in the context of social psychology research suggested that the new business creation could be explained as a conscious and intentional process in constant interaction with social environment (i.e., Bird, 1988; Krueger \& Brazeal, 1994; Krueger \& Carsrud, 1993; Krueger, Reilly, \& Carsrud, 2000; Liñán, Battistelli, \& Moriano, 2008). Licht \& Siegel (2006) point out that the origin of that framework could be traced to the Shapero \& Sokol's (1982) pioneering work. Shapero \& Sokol (1982) proposed that business creation was an activity culturally conditioned based on the system of values encouraged by society. In Shapero \& Sokol's opinion, human regular behavior is guided by a kind of inertia. Nevertheless, that inertia is, under certain circumstances, broken suddenly in a person's life span causing a type of displacement which forces the person to choose between different behavioral alternatives (Shapero, 1975). In the Shapero \& Sokol's "entrepreneurial event" model, the decision to create a new business depends on its desirability and feasibility (Shapero \& Sokol, 1982). The model was optimized approximately a decade later by Krueger \& Carsrud (1993) and Krueger \& Brazeal (1994) who joined the Shapero \& Sokol's entrepreneurial event model with the Theory of Reasoned Action (Ajzen \& Fishbein, 1980; Fishbein \& Ajzen, 1975). As a result, the new business creation process was understood as an intentional action mediated by the subjective perceptions of the potential entrepreneur.

\section{Bayesian Nets}

Bayesian networks originated in the field of artificial intelligence as statistical tools to model and manage uncertainty. From a technical point of view, Bayes nets (also referred as probabilistic causal nets, Bayesian expert systems, probabilistic expert systems, causal nets, belief nets or influence diagrams) are statistical tools belonging to the family of Highly Structured Stochastic Systems (Cowell, Dawid, Lauritzen \& Spiegelhalter, 1991) and they can represent both the quantitative and qualitative dimension of reality to solve problems or to make decisions under uncertainty.

Firstly, attending to its qualitative dimension, a Bayes net is a graph which means it is a graphical representation of a problem. Although there is no widely accepted consensus about the definition (i.e., Harary, 1969; Gould, 1988; Spirtes, Glymour, \& Scheines, 2000; Tutte, 1984; Xiang, 2002), we could say a graph is a pair $G=(V, E)$ where $V$ is a set of vertices, nodes or variables and $E$ is a set of edges. Additionally, a Bayes net is a specific type of graph called directed acyclic graph or DAG. The directionality of the graphical structure refers to the fact that links between variables or nodes are directed and it is represented by arrows. As a result, an arrow from a node $A$ that point to another $B$ means that $B$ depends (statistically) on $A$. On the other hand, in a DAG cycles or loops are not allowed, that is say if you begin a directed path from a particular node you could never come to the initial point. Taking into account these constraints, three types of basic connections are allowed in a Bayesian network: serial (also known as causal-chain), diverging (also known as common-cause model) and converging (also called common-effect model). These three basic structures behave differently when propagating probabilities and provide a robust architecture to update the model's parameters based on the principle of conditional independence.

After specifying qualitative structure it is necessary to determine the quantitative component in a Bayes net (Cowel et al., 1999). We could define the quantitative structure of a Bayesian network attending to three different aspects. First, probability is considered as a degree of belief about an event as opposed to the classical or frequentists view (i.e., Dixon, 1964; Heckerman, 1995). Secondly, a Bayes net entails a set of conditioned probability functions. That is to say, every variable in a Bayesian net is defined parametrically by a conditional probability function in the form of a conditional probability table (CPT) which represents the variable's state's probability as a function of others variables' states. Finally, Bayes' theorem is the basic rule to make inferences and to update probabilities in a Bayesian network. It comes from the concept of conditional probability applied to the intersection of related sets and it is due to the contributions of mathematician Thomas Bayes (1763). Bayes' rule is useful when we want to know something about an uncertain event by taking into account evidence from another related event.

Although Ward Edwards (1998) pointed out more than a decade ago that Bayesian networks had promising perspectives for psychology, these techniques are not very common in psychology literature as data analysis tools. However, there has been an increasingly amount of papers trying to highlight Bayes nets potential to serve as a normative reference model of human and animal causal cognition (i.e. Glymour, 2001, 2003; Gopnik, Glymour, Sobel, Schulz, Kushnir, \& Danks, 2004; Gopnik \& Schulz, L, 2004; Holyoak \& Cheng, 2011; Penn \& Povinelli, 2011). Additionally, despite the fact that a number of papers have been published dealing with an underlying substantive psychological point of view, most of them were focused on the computational perspective. Thus, efforts have been made to develop student models in the field of Intelligent Tutoring Systems (i.e., Conati, Gertner, \& VanLehn, 2002; Martin \& VanLehn, 1995; Mislevy \& Gitomer, 1996), in psycholinguistics (i.e., Narayan \& Jurafsky, 1998, 2002; Jurafsky, 1996), in psychological diagnostics (Mani, McDermmott, \& Valtorta, 1997), and to predict long-term consumers behaviors (Baesens et al., 2004).

\section{Objectives and Hypothesis}

Our main objective is to model entrepreneurial attitudes in 
women using Bayesian networks. Although the woman entrepreneur is not a new phenomenon (Gartner, 1985), and in spite of the fact that most of the research in the field try to study the role of the woman in the process of a new venture creation (i.e. Veciana, Aponte \& Urbano, 2005), it is also true that the phenomenon has received less attention than the generic study of entrepreneurship (Gewin, 2012; López, Ramirez, \& Casado, 2011). On the other hand, we want to use Bayesian networks as a relatively new technique to model entrepreneurial attitudes which provides some advantages compared with classical methods (i.e., López \& García, in press; López, García, Cano, Gea, \& De la Fuente, 2010).

As stated above, the Shapero's entrepreneurial event model identifies feasibility and desirability as the two main constructs affecting the intention to set up a new business (Krueger \& Brazeal, 1994; Krueger \& Carsrud, 1993; Shapero, 1982). As a result, we expect a Bayesian network representing those phenomena will predict new business creation intention reliably. Secondly, we propose to introduce a differentiation in the construct feasibility to accommodate earlier proposals of the entrepreneurial event model and recent theoretical developments. Specifically, as Shapero (1981) pointed out, we suggest considering feasibility as a composed construct integrated by a part referred to resources and another to opportunity (Cohen \& Winn, 2007; McMullen \& Shepherd, 2006). In that sense, entrepreneurial intention would depend on desirability and feasibility involving the latter one two components: opportunity (referred to how the new business is feasible in terms of creating new products or services relative to the potential competence) and resources (alluding to the degree in which the entrepreneur considers the set up of the new business will be possible in terms of economic, knowledge, and social resources). We propose it is practically useful to differentiate between these dimensions and we hypothesize the best model would be that one considering the two aspects of feasibility at the same time.

\section{Method}

\section{Participants}

A sample of 140 women entrepreneurs was asked to fill in an electronic questionnaire. Their ages ranged between 19 and 66 years $(M=42.38, S D=9.12)$ and they all were from Andalusia Autonomic Region in Spain. The object population for that research came from a directory of Andalusian woman entrepreneurs published in 2009 as a special issue in the magazine Mujer Emprendedora (Vol. 107, September, ISSN: 1575-9377). The original database contained 808 records of businesses managed by women in the Autonomic Region of Andalusia (Spain). After correcting repeated records and invalid information a final data set containing 587 records was used in the study. As a result, the response rate was $23.85 \%$.

\section{Instruments}

An electronic questionnaire developed with the LimeSurvey platform (Fa. Carsten Schmitz) was used. The questionnaire contained a set of individual items and scales that were used to create three different Bayesian networks. The items were taken from Morales' (2008) research about the academic entrepreneur.

To assess the relatives and peers influence we used two dichotomic items for which participants had to answer yes or not: my close relatives were or have been entrepreneurs, and I knew cases of other women in my close environment who had created their own business. Entrepreneurial intention was operationalised with the item which of the following statements best describes your case? There were three options in that item: 1) The decision to create a business was an unexpected one, it depended on the circumstances; 2) I had sometimes thought about creating my own business but I considered it as an unlikely possibility; 3) I had always had the idea of setting up a business in mind; however the first two alternatives were recoded into one category to differentiate between the true type of entrepreneur defined by Shane (2004).

The opportunity feasibility scale contained four items asking how important were relevant opportunity situations (for example, the discovery of a new method of production) when considering the creation of a new business (Chiesa \& Piccaluga, 2000; Heirman \& Clarysse, 2004). Resources feasibility was measured with eight Likert-type items from Autio \& Kauranen (1994) plus an item about personal assets. Six items were used to get a measure of desirability taken from Autio \& Kauranen (1994) and Radosevich (1995). A set of eleven potential obstacles (for example, creating a distribution network, raising money) were used to measure the degree in which woman entrepreneurs considered they faced difficulties when they created the business. All those scales were answered in a four point Liker-type scale where the options ranged from Not important at all (1) to Very important (4). Finally, a scale of perceived risk containing three items was used to evaluate the degree in which the entrepreneur considered the venture creation a risky choice for the company itself, personal capital and professional career development. Items were answered in a four point answer scale $(0=$ Nothing at all, $3=$ A lot $)$. Table 1 shows descriptive statistics for the scales scores.

\section{Procedure}

The directory was tabulated and incorporated to a database of potential participants in the LimeSurvey platform. Then, three different emails templates were developed to manage the invitation and data collection process. A personalized invitation mail was written for each participant indicating the name of the study and the aim of the research. The email of the survey designer was available in case any participant had a question or inquiry. Potential participants could access to the online questionnaire just by clicking in a hyperlink. This invitation email also contained a hyperlink to allow potential participants to

Table 1.

Descritive statistics and internal consistency coefficients.

\begin{tabular}{lccccc}
\hline \multirow{2}{*}{ Scales } & \multicolumn{5}{c}{ Statistics } \\
\cline { 2 - 6 } & $M$ & $S D$ & $\mathrm{LL \alpha}^{\mathrm{a}}$ & $\alpha^{\mathrm{b}}$ & $\mathrm{UL} \alpha^{\mathrm{c}}$ \\
\hline Opportunity feasibility & 11.21 & 2.41 & 0.468 & 0.570 & 0.659 \\
Resources feasibility & 19.53 & 4.70 & 0.669 & 0.728 & 0.782 \\
Desirability & 13.01 & 3.99 & 0.727 & 0.777 & 0.822 \\
Risk & 8.06 & 2.14 & 0.625 & 0.705 & 0.771 \\
Obstacles & 24.38 & 5.13 & 0.674 & 0.733 & 0.787 \\
\hline
\end{tabular}

a Lower limit confidence interval (90\%) for Cronbach's $\alpha$ coefficient of internal consistency (Feldt, Woodruff, \& Salih, 1987); ${ }^{\text {b} C r o n b a c h ' s ~} \alpha$ coefficient of internal consistency; c. Upper limit confidence interval (90\%) for Cronbach's $\alpha$ coefficient of internal consistency (Feldt et al., 1987). 
delete their record from our database and to avoid receiving more emails related with the research. A confirmation email was also written which was sent automatically from the server once the participant had successfully completed the questionnaire. Finally, a reminder email was also written to remain potential participants to fill in the survey. Two and four weeks after the first invitation email, a reminder email was sent to those participants who had not filled in the questionnaire. The final database contained information collected during a period of six weeks. No reward, apart from verbal acknowledges at the end of de questionnaire and in the confirmation email, was given to participants for participating in the study.

\section{Data Analysis}

The first step to take when defining a Bayesian network consists in defining its qualitative structure (Cowell et al., 1999). Bayesian network structural specification maybe defined using automatic procedures in the form of computational algorithms (i.e., Cooper \& Herskovits, 1992; Cowell et al.,1999; Spirtes et al., 2000) or based on the judgments of experts (i.e., Edwards, 1998; Nadkarny \& Shenoy, 2004). We have followed a theorydriven method to specify the models. Specifically, our models are based on the Shapero's entrepreneurial event model which suggests that entrepreneurial intention depends on feasibility and desirability (Krueger \& Brazeal, 1994; Krueger \& Carsrud, 1993; Shapero, 1975; Shapero \& Sokol, 1982). As a result, we tested three different models depicted in Figure 1. Model 1 could be considered the complete model in which entrepreneurial intention depends on desirability and either opportunity feasibility and resources feasibility. Additionally, desirability would depend on perceived risk, peer influence and relatives influence whereas the two types of feasibility would depend on perceived obstacles. Model 2 and 3 consider alternatively the relevance of opportunity and resources feasibility independently.

Scales total scores were discretised using percentile 33 and 66 in all the cases and parameter were assessed using the maximum likelihood estimation (or observed frequency estimation, OFE) corrected with the Laplace Law of succession (Greiner, Su, Shen, \& Zhou, 2005; Ng \& Jordan, 2002). We used Netica Application for Microsoft Windows (Norsys Software Corp.) version 4.16 to run the analysis. To evaluate the goodness of fit we used the hit classification rate, and scoring measures like the logarithmic loss, quadratic loss and spherical payoff (Pearl, 1978). The logarithmic loss ranges between zero and infinity indicating zero the best fit, the quadratic loss measure ranges between zero and two indicating zero the best fit whereas the spherical payoff varies between zero and one where one refers to the best fit. We also carried out a sensitivity analysis to evaluate the impact of each variable in the model on the entrepreneurial intentions variable. Entropy reduction (or mutual information) is referred to the expected reduction in the query variable (intentions in our case) due to a finding in any other variable of the model (Pearl, 1991). It varies between zero (meaning complete independence between the query and the instantiation variable) and the entropy value of the query without any evidence about the model. Secondly, we will also compute the variance of node belief and the RMS change of belief (Neapolitan, 1990). Both statistics range from zero to one where the closer the value to zero, the strongest the independence between the query and instantiation variable.
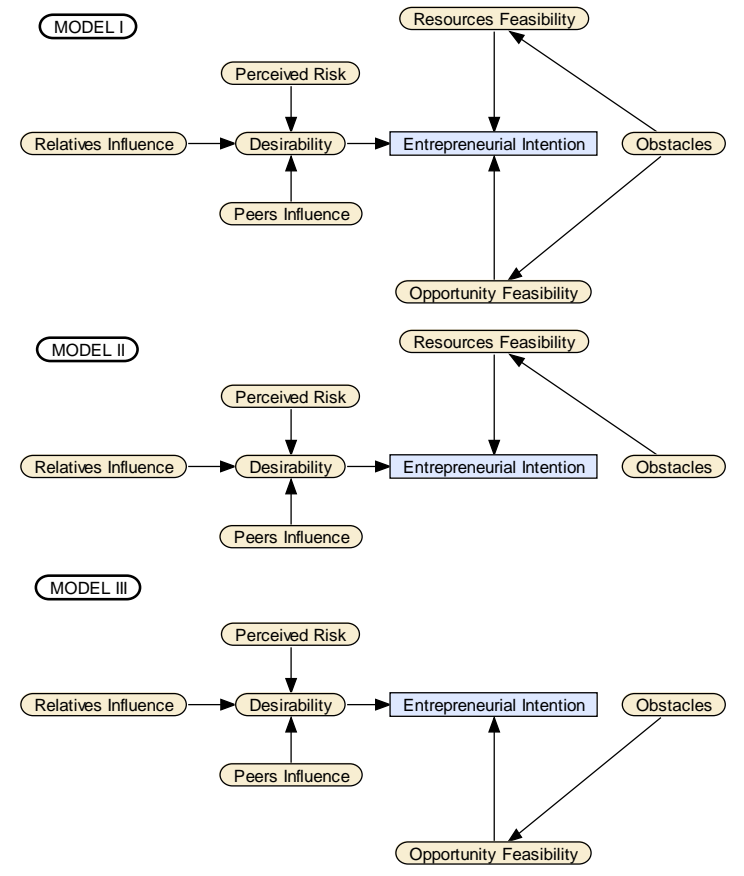

Figure 1.

Alternative models.

\section{Results}

Table 2 depicts the measurements of fit for the three used models. As can be seen, Model I containing variables referred to resources and opportunity feasibilities produces the better results. That model is able to correctly classify woman entrepreneurs in $75 \%$ of the cases. Additionally, logarithmic loss and quadratic loss measurements are the lower and the spherical payoff is the higher compared with the other two models. On the other hand, Model II (considering resources feasibility alone) and Model III (modeling opportunity feasibility) yield similar goodness of fit parameters. These results suggest that Model I considering feasibility as a composite construct of two different types of feasibilities (opportunity and resources) is a better model than those taking into account either of the dimensions separately.

In order to explore the relative influence of each variable in Model I on entrepreneurial intention, we carried out a sensitivity analysis whose results are shown in Table 3 . As can be appreciated, and as it is predicted by the theory, opportunity feasibility, desirability and resources feasibility are the three most influential variables in the model. There are a second set of variables, obstacles and relatives influence, accounting for a relatively important degree of influence whereas perceived risk and peers influence are the variables whose influence on entrepreneurial intention is lower.

\section{Discussion}

The most striking result in our research is that the differentiation between opportunity and resources feasibility is useful to predict entrepreneurial intention. Given that Model I produced better goodness of fit parameters, we could conclude feasibility is, at least for women entrepreneur, integrated by a dimension of opportunity and another one of resources. That evidence is 
Table 2.

Models goodness of fit.

\begin{tabular}{cccc}
\hline \multirow{2}{*}{ Statistics } & \multicolumn{3}{c}{ Model } \\
\cline { 2 - 4 } & I & II & III \\
\hline Hit rate & $75.00 \%$ & $71.74 \%$ & $72.83 \%$ \\
Logarithmic loss & 0.5406 & 0.5888 & 0.5689 \\
Quadratic loss & 0.3596 & 0.4002 & 0.3826 \\
Spherical payoff & 0.7983 & 0.7739 & 0.7847 \\
\hline
\end{tabular}

Table 3.

Sensitivity test results

\begin{tabular}{cccc}
\hline \multirow{2}{*}{ Variable } & \multicolumn{3}{c}{ Statistics } \\
\cline { 2 - 4 } & $\mathrm{ENT}^{\mathrm{a}}$ & $\mathrm{VAR}^{\mathrm{b}}$ & $\mathrm{RMS}^{\mathrm{c}}$ \\
\hline Opportunity Feasibility & $1.07 \times 10^{-2}$ & $3.67 \times 10^{-3}$ & $6.06 \times 10^{-2}$ \\
Desirability & $7.29 \times 10^{-3}$ & $2.49 \times 10^{-3}$ & $4.99 \times 10^{-2}$ \\
Resources Feasibility & $1.12 \times 10^{-3}$ & $3.84 \times 10^{-4}$ & $1.96 \times 10^{-2}$ \\
Obstacles & $7.60 \times 10^{-4}$ & $2.60 \times 10^{-4}$ & $1.61 \times 10^{-2}$ \\
Relatives Influence & $1.90 \times 10^{-4}$ & $6.53 \times 10^{-5}$ & $8.08 \times 10^{-3}$ \\
Perceived Risk & $7.00 \times 10^{-5}$ & $2.39 \times 10^{-5}$ & $4.89 \times 10^{-3}$ \\
Peers Influence & $3.00 \times 10^{-5}$ & $9.00 \times 10^{-6}$ & $3.00 \times 10^{-3}$ \\
\hline
\end{tabular}

${ }^{\mathrm{a}}$ Entropy reduction; ${ }^{\mathrm{b}}$ Variance of beliefs; ${ }^{\mathrm{C}} \mathrm{RMS}$ change of belief.

compatible with previous research on entrepreneurial attitude models (Krueger \& Brazeal, 1994; Krueger \& Carsrud, 1993; Krueger et al., 2000) and earlier theoretical proposals about opportunity feasibility (Shapero, 1981). Additionally, our results agree with recent emphasis on the opportunity facet of entrepreneurship (McMullen \& Shepherd, 2006) and future research should shed light on that phenomenon in an attitudinal holistic model of entrepreneurial intention.

The fact that our study was focused on the figure of the woman entrepreneur is a mixed blessing - it is worth researching the profile of woman entrepreneur given it seems that it had been a relatively neglected topic in the past research agenda (López et al., 2011), but we cannot discern if the observed results can be generalized to men. As regards to the first argument, we consider education as a key point to intervene in order to enhance the role of women in business creation and to strength our knowledge of the relationship between gender and business creation. For example, it has been recently shown that early school experiences have a determinant impact on entrepreneurial motivation amongst women (Díaz-Pérez \& González-Morales, 2011) so knowing and understanding the process underling the development of entrepreneurial attitudes in women will enhance our chances to intervene and improve the phenomenon. In that sense, the study of the potential entrepreneur woman is one of the strategic points we should consider in the research agenda. Finally, we would like to suggest the possibility women have in the new field of sustainable entrepreneurship (Shepherd \& Patzelt, 2011) because, as observed by Glodež, Hribar \& Dolinšek (2011), women seem to show better attitudes and predispositions to engage themselves in environmentally concerned jobs. As a consequence, future studies should try to elucidate if there exist any relationship between women entrepreneurs and environmental and social entrepreneurship.
Finally, we would like to stress our study is innovative in the sense Bayes nets are not quite common in psychological research as a statistical modeling tool. For example, Aguilera et al. (in press) noted that health sciences, life sciences, sociology and educative areas are far less concerned with using Bayesian networks as modeling tools when compared with computer science, mathematics or engineering. However, some contributions have been made to introduce Bayesian networks in the research area of the entrepreneurship psychology (López \& García, in press; López \& García, 2011; López, García, Cano \& De la Fuente, 2010). We propose to introduce progressively the use of Bayesian networks in psychological research as a modeling statistical tool and we hope our study presented here could contribute to that end.

\section{Acknowledgements}

The authors would like to thank Sigried Lievens whose comments and suggestions have inspired that research.

\section{REFERENCES}

Aguilera, P. A., Fernández, A., Fernández, R., Rumí, R., \& Salmerón, A. (2011). Bayesian networks in environmental modelling. Environmental Modeling and Software, 26, 1376-1388.

doi:10.1016/j.envsoft.2011.06.004

Ajzen, I., \& Fishbein, M. (1980). Understanding attitudes and predicting social behavior. Englewood, NJ: Prentice-Hall.

Autio, E., \& Kauranen, I. (1994). Technologist-entrepreneurs versus nonentrepreneurial technologists: Analysis of motivational triggering factors. Entrepreneurship y Regional Development, 6, 315-328. doi:10.1080/08985629400000019

Baesens, B., Verstraeten, G., Van den Poel, D., Egmont-Petersen, M., Van Kenhove, P., \& Vanthienen, J. (2004). Bayesian classifiers for identifying the slope of the customer life cycle of long-life customers. European Journal of Operational Research, 156, 508-523. doi:10.1016/S0377-2217(03)00043-2

Bayes, T. (1763). An essay towards solving a problem in the doctrine of chances. Philosophical Transactions, 53, 370-418. doi: $10.1098 /$ rstl.1763.0053

Bird, B. (1988). Implementing entrepreneurial ideas: The case for intention. Academy of Management Review, 13, 442-453.

Cantillon, R. (2010). An essay on economic theory. Auburn, AL: Ludwig von Mises Institute.

Chiesa, V., \& Piccaluga, A. (2000). Exploitation and diffusion of public research: The chase of academic spin-offs companies in Italy. $R \& D$ Management, 30, 329-339. doi:10.1111/1467-9310.00187

Cohen, B., \& Winn, M. I. (2007). Market imperfections, opportunity and sustainable entrepreneurship. Journal of Business Venturing, 22, 29-49. doi:10.1016/j.jbusvent.2004.12.001

Conati, C., Gertner, A., \& VanLehn, K. (2002). Using bayesian networks to manage uncertainty in student modeling. Modeling and User-Adapted Interaction, 12, 371-417. doi:10.1023/A:1021258506583

Cooper, G. F., \& Herskovits, E. (1992). A bayesian method for the induction of probabilistic networks from data. Machine Learning, 9, 309-347. doi:10.1007/BF00994110

Cowell, R. G, Dawid, A. P. Lauritzen, S. L \& Spiegelhalter, D. J. (1999). Probabilistic networks and expert systems. Harrisonburg, VA: Springer.

Díaz-Pérez, F. M., \& González-Morales, O. (2011). Desire of a managerial position and entrepreneurial motivation: The influence of gender and school type in the Canary Islands Young people. iBusiness, 3, 184-193.

Dixon, J. R. (1964). A programmed introduction to probability. New York: John Wiley \& Sons.

Edwards, W. (1998). Hailfinder. Tools for and experiences with bayesian normative modeling. American Psychologist, 53, 416-428. 
doi: 10.1037/0003-066X.53.4.416

Feldt, L. S., Woodruff, D. J., \& Salih, F. A. (1987). Statistical inferences for coefficient alpha. Applied Psychological Measurement, 11, 93-103. doi: $10.1177 / 014662168701100107$

Fishbein, M., \& Ajzen, I. (1975). Belief, attitude, intention, and behaveior: An introduction to theory and research. Reading, MA: AddisonWesley.

Fuller-Love, N. (2006). Management development in small firms. International Journal of Management Reviews, 8, 175-190. doi:10.1111/j.1468-2370.2006.00125.x

Gartner, W. B. (1985). A conceptual framework for describing the phenomenon of new venture creation. Academy of Management Review, 10, 696-706.

Gartner, W. B. (1988). "Who is an entrepreneur?" Is the wrong question. American Journal of Small Business, 12, 11-32.

Gewin, V. (2012). Women in business: Finding a way in. Nature, 481, 103-105. doi:10.1038/nj7379-103a

Glodež, N., Hribar, T. \& Dolinšek, S. (2011). Young people's (and women in particular) priorities and choices related to science and technology education-Case of Slovenia. Proceedings of the $4^{\text {th }}$ International Conference of Education, Research and Innovation, Madrid, 14-16 November 2011, 4778-4787.

Glymour, C. (2001). The mind's arrows. Bayes nets and graphical causal models in psychology. Cambridge, MA: MIT Press.

Glymour, C. (2003). Learning, prediction and causal Bayes nets. Trends in Cognitives Sciences, 7, 43-48. doi:10.1016/S1364-6613(02)00009-8

Gopnik, A., \& Schulz, L. (2004). Mechanisms of theory formation in young children. Trends in Cognitives Sciences, 8, 371-377. doi:10.1016/i.tics.2004.06.005

Gopnik, A., Glymour, C., Sobel, D. M., Schulz, L. E., Kushnir, T., \& Danks, D. (2004). A theory of causal learning in children: Causal and bayes nets. Psychological Review, 111, 3-32. doi:10.1037/0033-295X.111.1.3

Gottfredson, L. S. (1998). The general intelligence factor. Scientific American Presents, 9, 24-29.

Gould, R. (1988). Graph theory. Menlo Park, CA: Benjamin/Cummings.

Greiner, R., Su, X., Shen, B., \& Zhou, W. (2005). Structural extension to logistic regression: Discriminative parameter learning of belief net classifiers. Machine Learning, 59, 297-322. doi:10.1007/s10994-005-0469-0

Harary, F. (1969). Graph theory. Philippines: Westview Press.

Hayek, F. A. (1985). Richard Cantillon. The Journal of Libertarian Studies, 7, 217-247.

Hébert, R. F., \& Link, A. (1989). In search of the meaning of entrepreneurship. Small Business Economics, 1, 39-49. doi:10.1007/BF00389915

Heckerman, D. (1995). A tutorial on learning with bayesian networks (Tech. Rep. MS-TR-95-06). Redmon, WA: Microsoft Research.

Heirman, A., \& Clarysse, B. (2004). How and why do research-based start-ups differ at founding? A resource-based configurational perspective. Journal of Technology Transfer, 29, 247-268. doi:10.1023/B:JOTT.0000034122.88495.0d

Holyoak, K. J., \& Cheng, P. W. (2011). Causal learning and inference as a rational process: the new synthesis. Annual Review of Psychology, 62, 135-163. doi:10.1146/annurev.psych.121208.131634

Huefner, J. C., Hunt, H. K., \& Robinson, P. B. (1996). A comparison of four scales predicting entrepreneursihp. Academy of Entrepreneurship Journal, 1, 56-80.

Jurafsky, D. (1996). A probabilistic model of lexical and syntactic access and disambiguation. Cognitive Science, 20, 137-194. doi: $10.1207 / \mathrm{s} 15516709 \operatorname{cog} 2002 \_1$

Krueger, N. F., \& Brazeal, D. V. (1994). Entrepreneurial potential and potential entrepreneurs. Entrepreneurship Theory and Practice, 18, 91-104.

Krueger, N. F., \& Carsrud, A. L. (1993). Entrepreneurial intentions: Applying the theory of planned behavior. Entrepreneurship and Regional Development, 5, 315-330. doi:10.1080/08985629300000020

Krueger, N. F., Reilly, M. D., \& Carsrud, A. L. (2000). Competing models of entrepreneurial intentions. Journal of Business Venturing,
15, 411-432. doi:10.1016/S0883-9026(98)00033-0

Liñán, F., Battistelli, A., \& Moriano, J. A. (2008). Entrepreneurial intentions in Europe. In J. A. Moriano, M. Gorgievski \& M. Lukes (Eds.), Teaching psychology of entrepreneurship: Perspectives from six European countries (pp. 21-43). Madrid: National Open University (UNED).

López, J., \& García, J. (2011). Comparative performance of Bayes net and logistic regression to predict entrepreneurship. Communication presented at the 12th European Congress of Psychology, Istanbul, 4-8 July 2011.

López, J., \& García, J. (in press). Comparative study on entrepreneurial attitudes modelled with logistic regression and Bayes nets. The Spanish Journal of Psychology.

López, J., García, J., Cano, C. J., Gea, A. B., \& De la Fuente, L. (2010). A definition of potential entrepreneur from a probabilistic point of view. Proceedings of the XI Congreso de Metodología de las Ciencias Sociales \& de la Salud, Istanbul, 4-8 February 2010, 577-581.

López, J., Ramírez, A., \& Casado, M. P. (2011). Business characteristics correlating with the education level in women entrepreneurs. Proceedings of the $4^{\text {th }}$ International Conference of Education, Research and Innovation, Madrid, 14-16 November 2011, 5049-5046.

Mani, S., McDermmott, S., \& Valtorta, M. (1997). MENTOR: A bayesian model for prediction of mental retardation in newborns. Research in Developmental Disabilities, 18, 303-318. doi:10.1016/S0891-4222(97)00012-7

Martin, J., \& VanLehn, K. (1995). Sutdent assessment using bayesian nets. International Journal of Human-Computer Studies, 42, 575-591. doi:10.1006/ijhc. 1995.1025

McClelland, D. (1955). Some social consequences of achievement motivation. In M. R. Jones (Ed.), Nebraska symposium on motivation. Lincoln: University of Nebraska Press.

McClelland, D. (1961). The achieving society. New York: Free Press.

McKenzie, B., Ugbah, S., \& Smothers, N. (2007). "Who is an entrepreneur" is still the wrong question? Academy of Entrepreneurship Journal, 13, 23-43.

McMullen, J. S., \& Shepherd, D. A. (2006). Entrepreneurial action and the role of uncertainty in the theory of the entrepreneur. Academy of Management Review, 31, 132-152. doi:10.5465/AMR.2006.19379628

Mislevy, R. J., \& Gitomer, D. H. (1996). The role of probability-based inference in an intelligent tutoring system. User-Mediated and UserAdapted Interaction, 128, 253-282.

Morales, S. (2008). The academic entrepreneur and its decision to create a spin-off: An analysis of the Spanish case. Unpublished Doctoral Dissertation, Facultat d'Economia, Universitat de Valencia, Valencia.

Nadkarni, S., \& Shenoy, P. P. (2004). A causal mapping approach to constructing bayesian networks. Decision Support Systems, 38, 259281. doi:10.1016/S0167-9236(03)00095-2

Narayan, S., \& Jurafsky, D. (1998). Bayesian models of human sentence processing. Proceedings of the 20th Annual Meeting of the Cognitive Science Society. Madison, NJ: Lawrence Erlbaum Associates.

Narayan, S., \& Jurafsky, D. (2002). A bayesian model predicts human parse preference and reading times in sentence processing. Advances in Neural Information Processing, 14, 59-65.

Neapolitan, R. E. (1990). Probabilistic reasoning in expert systems: Theory and algorithms. New York: Wiley \& Sons.

Ng, A. Y., \& Jordan, M. I. (2002). On discriminative vs. generative classifiers: A comparation of logistic regresion and naive Bayes. Advances in Neural Information Processing Systems, 14, 841-848.

Pearl, J. (1978). An economic basis for certain methods of evaluating probabilistic forecasts. International Journal of Man-Machine Studies, 10, 175-183. doi:10.1016/S0020-7373(78)80010-8

Pearl, J. (1991). Probabilistic reasoning in intelligent systems: Networks of plausible inference (2nd ed.). San Mateo, CA: Morgan Kaufmann.

Penn, D. C. \& Povinelli, D. J. (2011). Causal cognition in human and nonhuman animals: A comparative, critical review. Annual Review of Psychology, 58, 97-118.

doi:10.1146/annurev.psych.58.110405.085555

Polopolus, L. C., \& Emerson, R. D. (1991). Entrepreneurship, sanctions, and labor contracting. Southern Journal of Agricultural Economics, 12, 57-68. 
Radosevich, R. (1995). A model for entrepreneurial spin-offs from public technology sources. International Journal Technological Management, 10, 879-893.

Robinson, P. B., Stimpson, D. V., Huefner, J. C., \& Hunt, H. K. (1991). An attitude approach to the prediction of entrepreneurship. Entrepreneurship Theory and Practice, 15, 13-31.

Rogoff, E. G., \& Lee, M. S. (1996). Does firm origin matter? An empirical examination of types of small business owners and entrepreneurs. Academy of Entrepreneurship Journal, 1, 1-17.

Samuelson, P. A. (1970). Economics (8th ed.). New York: McGrawHill.

Shane, S. (2004). Academic entrepreneurship: University spinoffs and wealth creation. Cheltenham, UK: Edward Elgar.

Shapero, A. \& Sokol, L. (1982). The social dimensions of entrepreneurship. In C. Kent, D. Sexton, \& K. H. Vesper (Eds.), The encyclopedia of entrepreneurship (pp. 72-90). Englewood Cliffs, NJ: Prentice-Hall.

Shapero, A. (1975). The displaced, uncomfortable entrepreneur. Psychology Today, 9, 83-133.

Shapero, A. (1981). Entrepreneurship. Key to self-renewing economies. Economic Development Commentary, 5, 19-23.

Shapero, A. (1985). Why entrepreneurship? A worldwide perspective.
Journal of Small Business Management, 23, 1-5.

Shepherd, D. A. \& Patzelt, H. (2011). The new field of sustainable entrepreneurship: Studying entrepreneurial action linking "what is to be sustained" with "what is to be developed". Entrepreneurship Theory and Practice, 35, 137-163. doi:10.1111/j.1540-6520.2010.00426.x

Spirtes, P., Glymour, C., \& Scheines, R. (2000). Causation, prediction and search (2nd ed.). Cambridge, MA: MIT Press.

Stanworth, J., Stanworth, C., Granger, B., \& Blyth, S. (1989). Who becomes an entrepreneur? International Small Business Journal, 8, 11-22. doi: $10.1177 / 026624268900800101$

Thompson, J. L. (2004). The facets of the entrepreneur: indentifying entrepreneurial potential. Management Decision, 42, 243-258. doi:10.1108/00251740410515861

Tutte, W. T. (1984). Graph theory. Cambridge: Cambridge University Press.

Veciana, J. M., Aponte, M., \& Urbano, D. (2005). University students' attitudes towards entrepreneurship: A two countries comparison. International Entrepreneurship and Management Journal, 1, 165-182. doi: $10.1007 / \mathrm{s} 11365-005-1127-5$

Xiang, Y. (2002). Probabilistic reasoning in multiagent systems. A graphical models approach. Cambridge: Cambridge University Press. doi:10.1017/CBO9780511546938 